\title{
An inactive Dispersin B probe for monitoring PNAG production in biofilm formation
}

\author{
Alexander Eddenden ${ }^{\mathrm{a}}$, Elena N. Kitova ${ }^{\mathrm{b}}$, John S. Klassen ${ }^{\mathrm{b}}$, Mark Nitz ${ }^{\mathrm{a}}$ \\ a Department of Chemistry, University of Toronto, 80 St. George St, Toronto, ON, Canada M5S \\ 3H6. Email address: mark.nitz@utoronto.ca; Tel: +1416-946-0640 \\ ${ }^{\mathrm{b}}$ Alberta Glycomics Centre and Department of Chemistry, University of Alberta, 11227 \\ Saskatchewan Dr. Edmonton, AB, Canada T6G 2G2
}

\section{SUPPORTING INFORMATION}

Cloning. The enzyme DspB and its catalytically inactive mutant DspB(E184Q) (DiPP) were expressed and purified starting from the plasmid pRC3 containing the $d s p B$ gene (pET29b plasmid containing residues 21-381 fused directly to a hexahistidine $\mathrm{C}$-terminal tag, under the control of a T7lac promoter) ${ }^{1,2}$.

GFP-fusions of DiPP were created by subcloning the $g f p$ gene from a plasmid encoding a GFPendosialidase fusion double mutant (pET15-GFP-EndoNF(E581A + R596A) $)^{3}$ into pRC3.

Primers specific to $g f p$ and $d s p B$ were used to obtain the gene encoding the N-terminal eGFPfusion of DiPP flanked by NdeI and KpnI sites in pET29b, denoted as pET29b-GFP-DspB ${ }_{\mathrm{E} 184 \mathrm{Q}}$. A SGGG linker and downstream thrombin cleavage site were used to link the two gene fragments.

Insertion of AviTags ${ }^{4}$ and generation of point mutants were accomplished using the NEB Q5® Site-Directed Mutagenesis Kit. The AviTag was inserted as an N-terminal tag using a GS linker to generate the plasmid pET29b-AviTag-GFP-DspB ${ }_{\mathrm{E} 184 \mathrm{Q}}$ (Fig. S7).

All sequences were validated by the sequencing service at the Centre for Applied Genomics (TCAG) managed by SickKids, Toronto, Canada.

Protein purification. Proteins were expressed from E. coli BL21(DE3) (New England Biolabs) cells. All DspB proteins were expressed and purified via the following protocol. Cells from overnight cultures were used to inoculate $600 \mathrm{~mL}$ LB (Miller) media with added kanamycin (50 $\mathrm{mg} \mathrm{L}{ }^{-1}$ ), which was grown at $37{ }^{\circ} \mathrm{C}$ under shaking conditions until an $\mathrm{OD}_{600}=0.6$, at which time isopropyl $\beta$-D-1-thiogalactopyranoside $(0.5 \mathrm{mM})$ was added to the cultures to induce expression. Cultures were grown for an additional 24 hours at $20{ }^{\circ} \mathrm{C}$ before harvesting.

MBP-BirA was expressed as previously described ${ }^{5}$.

Frozen cell pellets were lysed via mechanical grinding with celite (approximately 1:1 (w/w) wet cell pellet/celite) in the presence of protease inhibitor (cOmplete Mini, EDTA-free cocktail tablets, Roche) and $30 \mathrm{~mL}$ lysis buffer (20 mM sodium phosphate buffer $\mathrm{pH} 8.0,500 \mathrm{mM}$ sodium chloride, $10 \mathrm{mM}$ imidazole). Proteins containing a hexahistidine fusion-tag were purified via Ni-NTA resin (QIAGEN) and elution with imidazole $(100 \mathrm{mM})$. Protein identities were confirmed by SDS-PAGE analysis and ESI-MS using an Agilent 6538 Q-TOF mass spectrometer. Typical yields from $1 \mathrm{~L}$ of cell culture ranged from $30-50 \mathrm{mg}$ of non-fusion DspB variants and 5-10 mg GFP-DspB fusion constructs. If deemed necessary, proteins underwent 
additional rounds of purification on BioRad ENrich Q ion exchange and ENrich SEC70 10×300 $\mathrm{mm}$ size exclusion columns before storage at $-20^{\circ} \mathrm{C}$ in $10 \%(\mathrm{v} / \mathrm{v})$ glycerol.

PNAG oligosaccharide purification. Synthesis of the PNAG oligosaccharides was performed as previously described ${ }^{6}$. Briefly, a concentrated solution of $N$-acetylglucosamine $(1 \mathrm{~g})$ in $70 \%$ $\mathrm{HF}$-pyridine ( $1 \mathrm{~g}$ in $0.7 \mathrm{~mL})$ was incubated with stirring at room temperature for 5 days and quenched by pouring into a calcium carbonate suspension $(2 \mathrm{~g})$ on ice with stirring. Subsequent washing and filtration steps gave a mixture of poly- $\beta-1,6-N$-acetyl-D-glucosamine oligomers up to 12 units in length.

Size exclusion fractionation of the mixture was performed on a Bio-Gel P4 (BioRad) size exclusion column $(2.5 \mathrm{~cm}$ I.D. $\times 120 \mathrm{~cm}, 45-90 \mu \mathrm{m}$ particle size $)$ using a flow rate of $0.7 \mathrm{ml}$ $\min ^{-1}$ deionized water and monitoring absorbance at $215 \mathrm{~nm}$.

Fractions were analyzed by MALDI to determine oligomer lengths. PNAG oligomers samples were dried using 2,5-dihydroxybenzoic acid (Sigma) as matrix, and mass spectra were acquired using a Bruker Autoflex Speed MALDI-TOF instrument.

Intrinsic fluorescence quenching binding assay. PNAG oligomer binding to DiPP was monitored by intrinsic tryptophan fluorescence quenching. Fluorescence measurements were performed on a Fluorolog-3 spectrofluorometer. Samples were excited at a wavelength of 295 $\mathrm{nm}$ and measurements were recorded using a peak emission wavelength of $344 \mathrm{~nm}$. Scan rate was $0.5 \mathrm{~nm} \mathrm{~s}^{-1}$ with bandpasses of $2 \mathrm{~nm}$. Samples consisted of $50 \mu \mathrm{M}$ DiPP in assay buffer (50 $\mathrm{mM}$ sodium phosphate buffer $\mathrm{pH} 8.0,50 \mathrm{mM}$ sodium chloride) with titrations from a $50 \mathrm{mM}$ solution of PNAG oligomer in assay buffer. Samples were left to equilibrate for 2 minutes before fluorescence was measured. Data collected was corrected for inner filter effect and dilutions, and fit to a single-site binding equation: $\frac{F_{0}-F}{F_{0}}=\frac{F_{0}-F_{c}}{F_{0}} \times \frac{[L]}{K_{d}+[L]}$ where $\frac{F_{0}-F}{F_{0}}$ is the amount of quenching relative to the initial fluorescence $F_{0}$ at some PNAG oligomer concentration $[L] . \mathrm{F}_{\mathrm{c}}$ is the measured fluorescence intensity at each titration point corrected for inner filter and scattering effects. $K_{d}$ represents the calculated dissociation constant of the interaction. Each binding curve represents data taken from 3 independent binding experiments.

ESI-MS binding assay. The dissociation constants $\left(\mathrm{K}_{\mathrm{d}}\right)$ for the DiPP-PNAG oligomer interactions were measured using the direct ESI-MS assay. ${ }^{7}$ Solutions of DiPP $(5.7 \mu \mathrm{M})$ and a given ligand $(20 \mu \mathrm{M}, 40 \mu \mathrm{M}, 60 \mu \mathrm{M}, 80 \mu \mathrm{M}$ and $100 \mu \mathrm{M})$ were prepared in $200 \mathrm{mM}$ aqueous ammonium acetate ( $\mathrm{pH}$ 6.8). Binding measurements were carried out in positive ion mode using a Synapt G2S ESI-Q-IMS-TOF mass spectrometer (Waters, Manchester, UK) equipped with nanoflow ESI (nanoESI) source. NanoESI was performed by applying a voltage of $\sim 1 \mathrm{kV}$ to a platinum wire inserted into the nanoESI tip, which was produced from a borosilicate glass capillary (1.0 mm o.d., $0.68 \mathrm{~mm}$ i.d.) pulled to $\sim 5 \mu \mathrm{m}$ o.d. using a $\mathrm{P}-1000$ micropipette puller (Sutter Instruments, Novato, CA). The source temperature and gas flow rate was $60{ }^{\circ} \mathrm{C}$ and $2 \mathrm{~mL} \mathrm{~min}^{-1}$, respectively. The Cone, Trap and Transfer voltages were $20 \mathrm{~V}, 3 \mathrm{~V}$ and $1 \mathrm{~V}$, respectively. MassLynx software (version 4.1) was used for data acquisition and processing.

The $\mathrm{K}_{\mathrm{d}}$ for protein $(\mathrm{P})$ - ligand $(\mathrm{L})$ binding was calculated from the abundance ratio of Lbound to free $\mathrm{P}$ ions (i.e., $R$ ), measured by ESI-MS: 


$$
\begin{gathered}
R=\frac{A b(\mathrm{PL})}{A b(\mathrm{P})}=\frac{[\mathrm{PL}]}{[\mathrm{P}]} \\
\mathrm{K}_{\mathrm{d}}=\frac{[\mathrm{P}][\mathrm{L}]}{[\mathrm{PL}]}=\frac{[\mathrm{L}]_{0}}{R}-\frac{[P]_{0}}{R+1}
\end{gathered}
$$

where $[\mathrm{P}]_{0}$ and $[\mathrm{L}]_{0}$ are initial concentrations of protein and ligand, correspondingly. Non-specific

\begin{tabular}{|c|c|c|}
\hline \multicolumn{3}{|c|}{ Dissociation constants $\left(\mathrm{K}_{d}\right)$ measured using direct ESI-MS binding assay $([\mathrm{DiPP}]=5.7 \mu \mathrm{M})$} \\
\hline PNAG oligomer & $\begin{array}{c}\text { Concentration of PNAG } \\
\text { oligomer }(\mu \mathrm{M})\end{array}$ & $\mathbf{K}_{\mathrm{d}}(\mathbf{m M})$ \\
\hline \multirow{6}{*}{ 4-mer } & 20 & $0.7 \pm 0.4$ \\
\hline & 40 & $0.9 \pm 0.3$ \\
\hline & 60 & $0.9 \pm 0.4$ \\
\hline & 80 & $0.9 \pm 0.3$ \\
\hline & 100 & $1.8 \pm 0.7$ \\
\hline & Average & $1.0 \pm 0.4$ \\
\hline \multirow[t]{6}{*}{ 6-mer } & 20 & $0.8 \pm 0.2$ \\
\hline & 40 & $0.9 \pm 0.4$ \\
\hline & 60 & $1.0 \pm 0.1$ \\
\hline & 80 & $1.0 \pm 0.2$ \\
\hline & 100 & $1.2 \pm 0.3$ \\
\hline & Average & $1.0 \pm 0.2$ \\
\hline \multirow[t]{6}{*}{ 8-mer } & 20 & $1.1 \pm 0.1$ \\
\hline & 40 & $1.6 \pm 0.4$ \\
\hline & 60 & $1.2 \pm 0.2$ \\
\hline & 80 & $1.3 \pm 0.3$ \\
\hline & 100 & $1.2 \pm 0.1$ \\
\hline & Average & $1.3 \pm 0.2$ \\
\hline
\end{tabular}
protein-ligand binding was corrected as described in Sun et al. ${ }^{7 \mathrm{c}}$

Binding assays involving ESI-MS detection and quantification were performed as previously described $^{7}$. Briefly, DiPP-PNAG oligosaccharide complexes are quantitatively detected in the gas phase during electrospray ionization, and the relative proportions of bound and free DiPP were used to calculate the dissociation constant of the interaction (Table S1).

Bacterial PNAG binding assay. Biotinylation of AviTag was performed following recommended reaction conditions from Avidity. The AviTag-GFP-DiPP protein to be biotinylated was buffer exchanged into BirA reaction buffer (50 mM bicine buffer $\mathrm{pH} 8.3,10$ $\mathrm{mM}$ ATP, $10 \mathrm{mM}$ magnesium acetate, $50 \mu \mathrm{M}$ D-biotin) to a final concentration of $40 \mu \mathrm{M}$. Biotinylation reactions were incubated overnight at room temperature in the presence of $0.4 \mu \mathrm{M}$ MBP-BirA. Extent of reaction was assessed by the degree of gel shift in SDS-PAGE when streptavidin was added ${ }^{8-10}$ (Fig. S8), and confirmed by ESI-MS (data not shown). It was not found necessary to add additional D-biotin to reactions as biotinylation appeared quantitative under these conditions. Reaction mixtures were desalted using PD-10 desalting columns (GE Healthcare) to avoid excess biotin competing with biotinylated protein for streptavidin binding sites. 
Tetramerization of the biotinylated AviTag-GFP-DiPP was performed by addition of streptavidin (Promega) to the biotinylated GFP-DiPP solution. The amount of streptavidin added was limiting (6:1 biotinylated protein/streptavidin tetramer) to ensure maximal saturation of all streptavidin binding sites. The mixtures were incubated for 1 hour before separation on an ENrich SEC650 $10 \times 300 \mathrm{~mm}$ size exclusion column (BioRad). High molecular weight species were analyzed by SDS-PAGE and native-PAGE, with the latter also used to view GFP fluorescence using a G:BOX Chemi XT4 gel imager (Fig. S9). The tetramerized AviTag-GFP-DspB(E184Q) construct is referred to as tetra-GFP-DiPP onwards.

E. coli MG1655 csr A::kanB and E. coli BW25113 strains used in the bacterial PNAG binding assay were grown from overnight cultures in $50 \mathrm{~mL} \mathrm{LB(Miller)} \mathrm{media} \mathrm{at} 37^{\circ} \mathrm{C}$ with shaking. $E$. coli BW25113 strain was used as the wild-type analog of the E. coli MG1655 csrA::kanB with the expectation that the genome variations between the parent MG1655 strain and the derived BW25113 strain ${ }^{11}$ were inconsequential to the phenotype under study. At an $\mathrm{OD}_{600}=1.5-2$ (approximately 3 hours of growth) cultures were harvested at $6500 \mathrm{~g}$. Cells were resuspended in DiPP binding buffer (50 mM sodium phosphate buffer $\mathrm{pH} 5.8,0.5 \%$ (w/v) BSA, PBS pH 5.8) to varying $\mathrm{OD}_{600}$ values and $0.5 \mathrm{~mL}$ of each resuspension was aliquoted into separate microcentrifuge $0.45 \mu \mathrm{m}$ filter tubes (ref. CLS8163, Corning Costar). There was a single replicate per cell density value per culture grown, with a corresponding tube containing the same cell density to be treated solely with buffer without GFP-DiPP; these acted as controls for cell autofluorescence ${ }^{12}$. All centrifugation steps with filter tubes were performed at $4{ }^{\circ} \mathrm{C}$ and $4000 \mathrm{~g}$. All solutions were made up in the cell binding buffer described earlier.

Cells were washed once with buffer before resuspension in GFP-DiPP $(150 \mu \mathrm{L}, 0.1 \mu \mathrm{M})$ solution (or buffer for autofluorescence controls). Filter tubes were incubated at room temperature for 30 minutes before being spun down and the filtrate collected. This process was then repeated with buffer to wash away any weak binding interactions. Cells were then resuspended in DspB (150 $\mu \mathrm{L}, 50 \mu \mathrm{M}$ ) solution and incubated at room temperature for 30 minutes before being spun down and the third and final filtrate collected. The concentration of GFP-DiPP in collected filtrates was quantified using a CLARIOstar microplate reader (BMG Labtech) to measure GFP fluorescence (470 $\mathrm{nm}$ excitation wavelength, $515 \mathrm{~nm}$ emission wavelength, $15 \mathrm{~nm}$ and $20 \mathrm{~nm}$ bandpasses respectively). Data for each cell density value was blank subtracted using the autofluorescence controls, and the fluorescence values were converted to GFP-DiPP concentration values using a standard curve of GFP-DiPP made up in cell binding buffer. Bacterial PNAG binding assays were performed in triplicate for each probe construct used. Reproducibility of each replicate was assessed by comparing the summed fluorescence intensities of all collected filtrates against the initial fluorescence intensity of the $0.1 \mu \mathrm{M}$ GFP-DiPP labelling solution; the initial signal should be reconstituted if no bleaching/irreversible binding has occurred. Addition of $0.5 \%(\mathrm{w} / \mathrm{v}) \mathrm{BSA}$ to cell binding buffer was found to prevent loss of GFP signal through passivation of the cellulose acetate filter membrane. A graphical description of the general protocol can be found in Figs. 2 and S4.

Biofilm assay. E. coli MG1655 csrA::kanB cells from overnight cultures were used to inoculate LB(Miller) media with added kanamycin $(1: 100 \mathrm{v} / \mathrm{v})$. Aliquots of $200 \mu \mathrm{L}$ were pipetted into a flat-bottom 96 well plate (ref. 353072, Falcon) and left to grow without shaking at room temperature for 24 hours. Media was then dumped out carefully and the wells refilled with 200 $\mu \mathrm{L}$ of DspB or DiPP in activity buffer $(50 \mathrm{mM}$ sodium phosphate buffer $\mathrm{pH} 5.8,50 \mathrm{mM}$ sodium chloride). The plate was incubated for 30 minutes at room temperature before the enzyme 
solutions were carefully dumped out. Wells were then washed gently with deionized water and then stained with $200 \mu \mathrm{L}$ of a $0.1 \%$ (w/v) crystal violet solution for 15 minutes. Excess crystal violet was gently washed out with deionized water and the stained biofilms were air-dried overnight (Fig. S5). For quantification, crystal violet was resolubilized with $200 \mu \mathrm{L}$ of $30 \%$ (v/v) acetic acid in water for 15 minutes, and $100 \mu \mathrm{L}$ from each well was transferred to a new 96 well plate already containing $100 \mu \mathrm{L}$ of $30 \%(\mathrm{v} / \mathrm{v})$ acetic acid solution in each well. Absorbance at $550 \mathrm{~nm}$ was measured on a plate reader (Fig. S5). Nonspecific staining of empty wells by crystal violet was negligible.

Confocal microscopy analysis. E. coli MG1655 $\operatorname{csr} A$ ::kanB planktonic cells were grown from overnight cultures in $50 \mathrm{~mL}$ LB(Miller) media at $37^{\circ} \mathrm{C}$ with shaking. At specific timepoints based on $\mathrm{OD}_{600}$ ( 2 hours, $\mathrm{OD}_{600}=0.5-0.7$ for early log phase; 4 hours, $\mathrm{OD}_{600}=1.5-2.0$ for mid$\log$ phase) an aliquot of cell culture was taken and treated with $0.2 \mu \mathrm{M}$ GFP-DiPP variant $+0.1 \%$ BSA (w/v) for 10 minutes. Several microlitres of stained cell culture was then added onto a PBSbased $1 \%(\mathrm{w} / \mathrm{v})$ agarose pad (preparation has been previously described ${ }^{13}$ ). When treating samples with DspB, $20 \mu \mathrm{L}$ of $20 \mu \mathrm{M}$ DspB solution in PBS pH 5.8 was added to the opposite face of the agarose pad. When all excess liquid had soaked into the agarose the pad was sandwiched between two sterile acid-washed borosilicate coverslips and the edges sealed with Vaseline-lanolin-paraffin mixture (VALAP, 1:1:1 w/w/w) to prevent evaporation. Microscopy images were obtained with an AxioObserver.Z1 microscope equipped with a Plan-Apochromat $100 \times / 1.40$ Oil DIC M27 objective.

E. coli MG1655 csr $A:$ :kanB biofilms were grown in a 6 well plate containing $5 \mathrm{~mL}$ LB(Miller) media with added kanamycin inoculated with overnight cultures. Each well also contained a sterile acid-washed borosilicate cover slip. Biofilms were left to grow without shaking at room temperature for 24 hours.

S. epidermidis SE801 biofilms were grown in a 6 well plate containing $5 \mathrm{~mL}$ TSB media inoculated with overnight cultures. Each well also contained a sterile acid-washed borosilicate cover slip. Biofilms were left to grow without shaking at $37^{\circ} \mathrm{C}$ for 24 hours.

$P$. aeruginosa PAO1 and PA14 biofilms were grown in a 6 well plate containing $5 \mathrm{~mL}$ LB(no $\mathrm{NaCl})$ media inoculated with overnight cultures. Each well also contained a sterile acid-washed borosilicate cover slip. Biofilms were left to grow without shaking at $25^{\circ} \mathrm{C}$ for 24 hours. In addition to the coverslip-attached biofilm growth, a pellicle formed on the liquid surface, requiring removal prior to coverslip retrieval.

Microscopy sample preparation for all biofilms followed the same protocol and was performed aseptically. Coverslips were washed with PBS to detach loose cells and immersed in a $10 \mathrm{mg} \mathrm{L}^{-1}$ DAPI solution in PBS for 15 minutes in the dark. Excess liquid on coverslips was then removed carefully and biofilms were labelled with $50 \mu \mathrm{L}$ of a $0.5 \mu \mathrm{M}$ GFP-DiPP variant $+0.1 \%(\mathrm{w} / \mathrm{v})$ BSA solution in PBS for 10 minutes. Coverslips were washed twice more with PBS and a PBSbased $1 \%(\mathrm{w} / \mathrm{v})$ agarose $\mathrm{pad}^{13}$ was carefully placed on top of the biofilms. When treating samples with DspB, $20 \mu \mathrm{L}$ of $20 \mu \mathrm{M}$ DspB solution in PBS pH 5.8 was added to the opposite face of the agarose pad. When all excess liquid had soaked into the agarose a second sterile acid-washed borosilicate coverslip was placed on top of the pad and the edges sealed with Vaseline-lanolinparaffin mixture (VALAP, 1:1:1 w/w/w) to prevent evaporation. Microscopy images were obtained with an AxioObserver.Z1 microscope equipped with a Plan-Apochromat 40×/1.40 Oil DIC (UV) VIR-IR M27 objective. 
Time course experiment. Time course of $E$. coli $\operatorname{csr} A:: k a n B$ was performed using planktonic cells grown from overnight cultures and inoculated into $50 \mathrm{~mL} \mathrm{LB}$ (Miller) media at $37^{\circ} \mathrm{C}$. Cultures were grown for 2 hours with shaking. Aliquots were then taken and treated with $0.2 \mu \mathrm{M}$ tetra-GFP-DiPP $+0.1 \%(\mathrm{w} / \mathrm{v})$ BSA. Several microlitres of stained cell culture was added onto a LB(Miller) media-based $1 \%(\mathrm{w} / \mathrm{v})$ agarose pad with kanamycin and $0.2 \mu \mathrm{M}$ tetra-GFP-DiPP presoaked in. When all excess liquid had soaked into the agarose the pad was sandwiched between coverslips and the edges sealed with VALAP to prevent evaporation. Microscopy images were collected once a minute for several hours, utilizing Zeiss Definite Focus. 2 to avoid out of plane drift, and minimizing exposure time and laser intensity to avoid perturbing cell growth.

\section{SUPPORTING REFERENCES}

(1) Ramasubbu, N.; Thomas, L. M.; Ragunath, C.; Kaplan, J. B. Structural Analysis of Dispersin B, a Biofilm-Releasing Glycoside Hydrolase from the Periodontopathogen Actinobacillus Actinomycetemcomitans. J. Mol. Biol. 2005, 349 (3), 475-486. https://doi.org/10.1016/j.jmb.2005.03.082.

(2) Manuel, S. G. A.; Ragunath, C.; Sait, H. B. R.; Izano, E. A.; Kaplan, J. B.; Ramasubbu, N. Role of Active-Site Residues of Dispersin B, a Biofilm-Releasing $\beta$-Hexosaminidase from a Periodontal Pathogen, in Substrate Hydrolysis. FEBS J. 2007, 274 (22), 5987-5999. https://doi.org/10.1111/j.1742-4658.2007.06121.x.

(3) Yu, C. C.; Hill, T.; Kwan, D. H.; Chen, H. M.; Lin, C. C.; Wakarchuk, W.; Withers, S. G. A Plate-Based High-Throughput Activity Assay for Polysialyltransferase from Neisseria Meningitidis. Anal. Biochem. 2014, 444 (1), 67-74. https://doi.org/10.1016/j.ab.2013.09.030.

(4) Beckett, D.; Kovaleva, E.; Schatz, P. J. A Minimal Peptide Substrate in Biotin Holoenzyme Synthetase-Catalyzed Biotinylation. Protein Sci. 1999, 8, 921-929.

(5) Li, Y.; Sousa, R. Expression and Purification of E. Coli BirA Biotin Ligase for in Vitro Biotinylation. Protein Expr. Purif. 2012, 82 (1), 162-167.

https://doi.org/10.1016/j.pep.2011.12.008.

(6) Leung, C.; Chibba, A.; Gómez-Biagi, R. F.; Nitz, M. Efficient Synthesis and Protein Conjugation of $\beta-(1 \rightarrow 6)-d-N$-Acetylglucosamine Oligosaccharides from the Polysaccharide Intercellular Adhesin. Carbohydr. Res. 2009, 344 (5), 570-575. https://doi.org/10.1016/j.carres.2008.12.021.

(7) a) El-Hawiet, A.; Kitova, E. N.; Klassen, J. S. Quantifying Carbohydrate-Protein Interactions by Electrospray Ionization Mass Spectrometry Analysis. Biochemistry 2012, 51 (21), 4244-4253. https://doi.org/10.1021/bi300436x. b) Kitova, E. N.; El-Hawiet, A.; Schnier, P. D.; Klassen, J. S. J Am. Soc. Mass Spectrom. 2012, 23, 431-441, c) Sun, J. X.; Kitova, E. N.; Wang, W. J.; Klassen, J. S. Anal. Chem. 2006, 78, 3010-3018

(8) Jain, J.; Veggiani, G.; Howarth, M. Cholesterol Loading and Ultrastable Protein Interactions Determine the Level of Tumor Marker Required for Optimal Isolation of Cancer Cells. Cancer Res. 2013, 73 (7), 2310-2321. https://doi.org/10.1158/0008- 
5472.CAN-12-2956.

(9) Gautier, A.; Hinner, M. J. Site-Specific Protein Labeling: Methods and Protocols. In SiteSpecific Protein Labeling: Methods and Protocols; 2015; Vol. 1266, pp 171-184. https://doi.org/10.1007/978-1-4939-2272-7.

(10) Sorenson, A. E.; Askin, S. P.; Schaeffer, P. M. In-Gel Detection of Biotin-Protein Conjugates with a Green Fluorescent Streptavidin Probe. Anal. Methods 2015, 7 (5), 2087-2092. https://doi.org/10.1039/c4ay02666g.

(11) Grenier, C.; Matteau, F.; Baby, D.; Rodrigue, V. Complete Genome Sequence of Escherichia Coli BW25113. Genome Announc 2014, 2 (5), 1038-1052. https://doi.org/10.1128/genomeA.01038-14.

(12) Mihalcescu, I.; Van-Melle Gateau, M.; Chelli, B.; Pinel, C.; Ravanat, J. L. Green Autofluorescence, a Double Edged Monitoring Tool for Bacterial Growth and Activity in Micro-Plates. Phys. Biol. 2015, 12 (6), 66016. https://doi.org/10.1088/14783975/12/6/066016.

(13) Skinner, S. O.; Sepúlveda, L. A.; Xu, H.; Golding, I. Measuring MRNA Copy Number in Individual Escherichia Coli Cells Using Single-Molecule Fluorescent in Situ Hybridization. Nat. Protoc. 2013, 8 (6), 1100-1113. https://doi.org/10.1038/nprot.2013.066. 


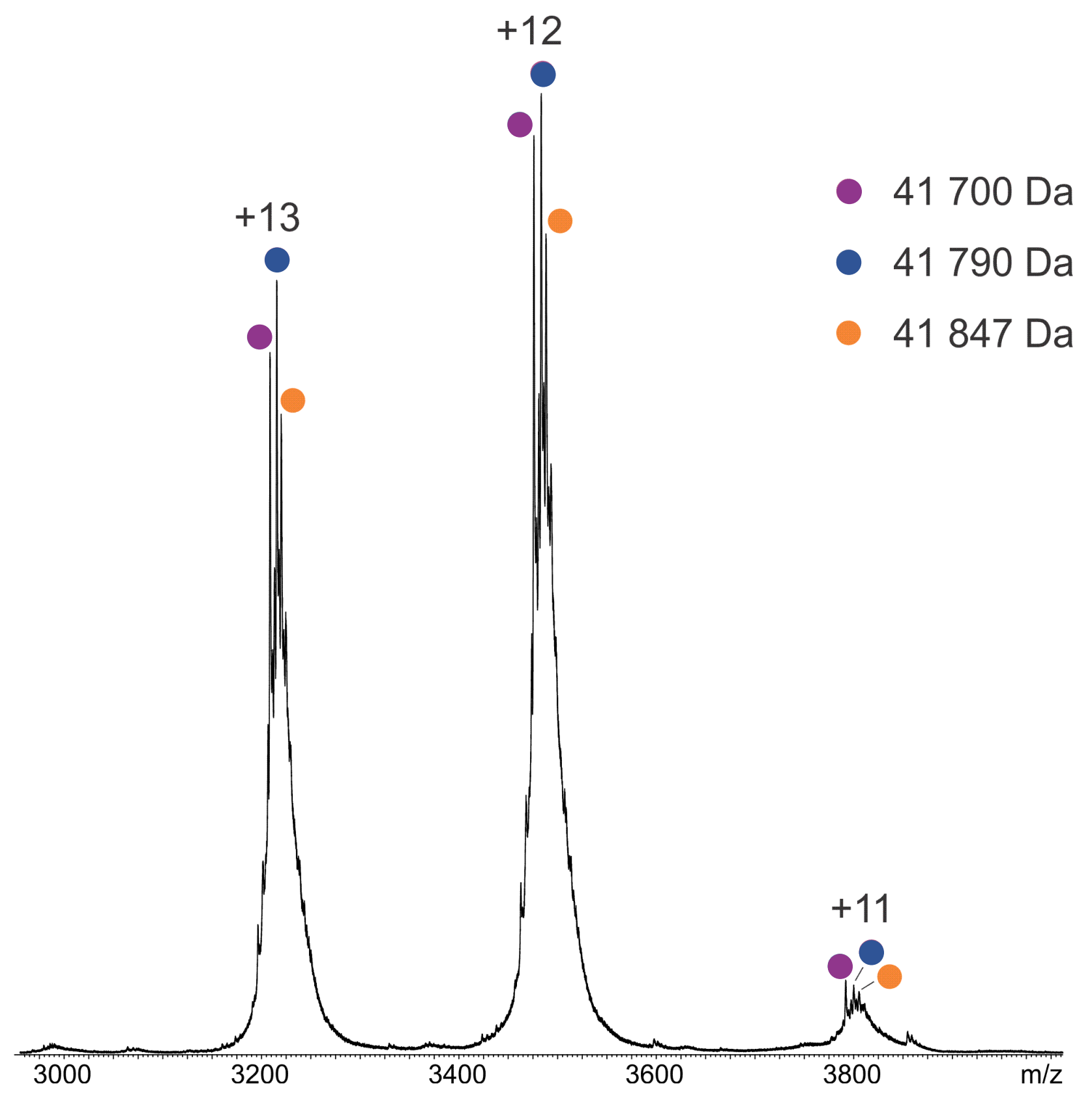


Figure S1. Electrospray mass spectrum obtained in positive mode for aqueous ammonium acetate (200 mM, pH 7) solution of DiPP $(5.7 \mu \mathrm{M})$. Molecular weights of the three major DiPP species are shown

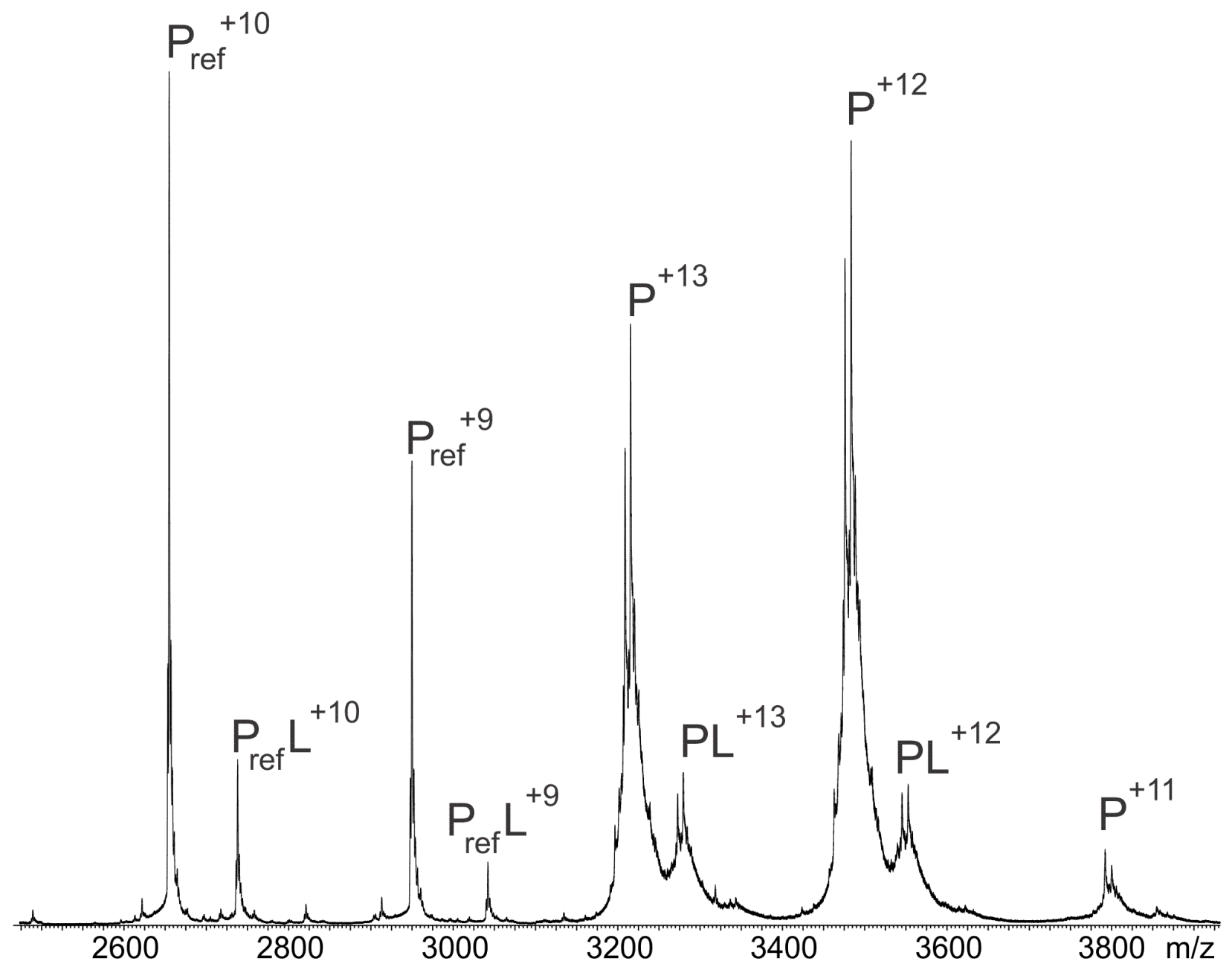

Figure S2. Electrospray mass spectrum obtained in positive mode for aqueous ammonium acetate (200 mM, pH 7) solution of $\operatorname{DiPP}(\mathrm{P}, 5.7 \mu \mathrm{M})$, reference protein (Se155-4 single chain variable fragment, $\mathrm{P}_{\text {ref }}, 1 \mu \mathrm{M}$ ) and PNAG tetramer $(\mathrm{L}, 60 \mu \mathrm{M})$. 


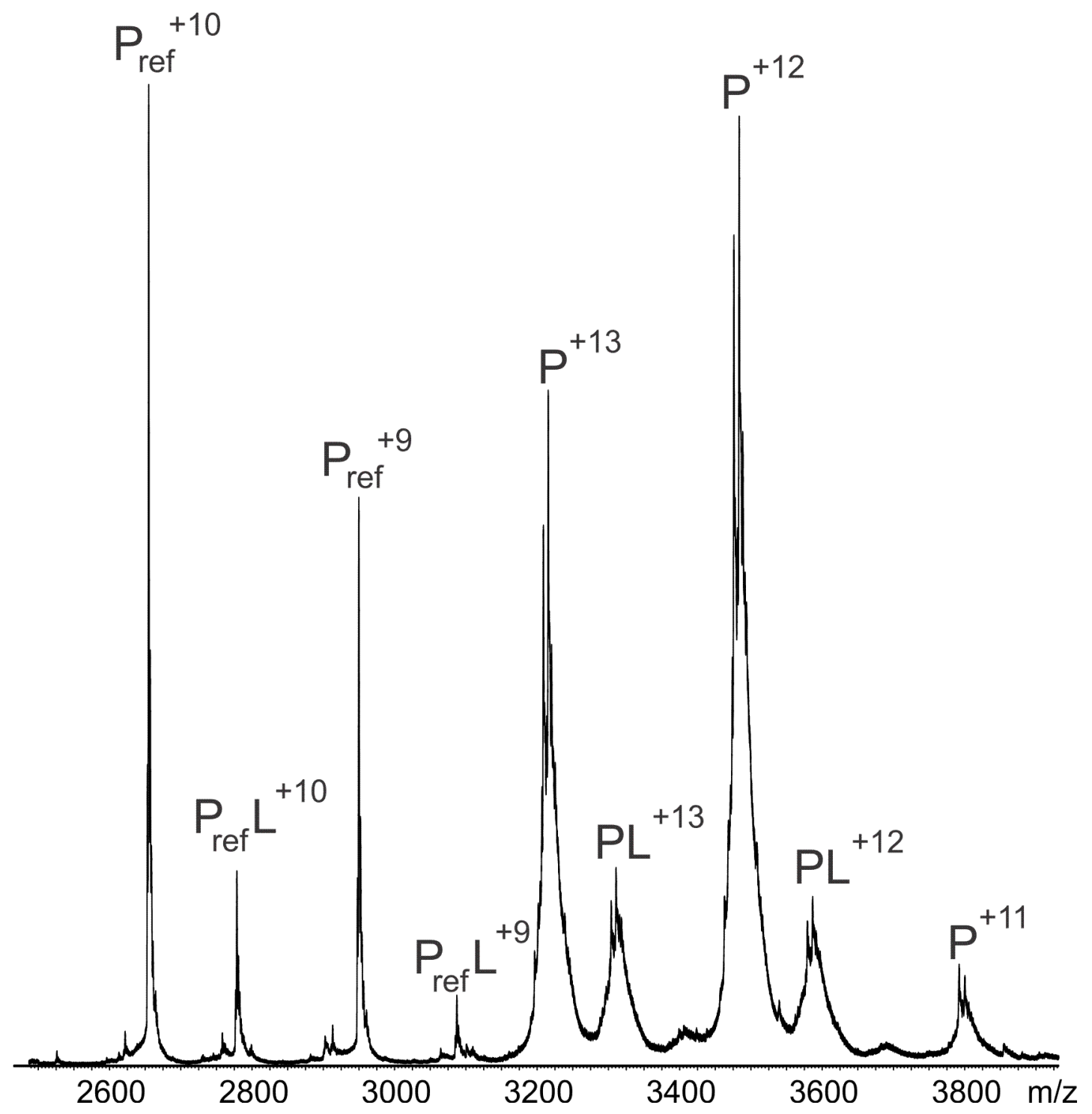

Figure S3. Electrospray mass spectrum obtained in positive mode for aqueous ammonium acetate (200 mM, pH 7) solution of $\operatorname{DiPP}(\mathrm{P}, 5.7 \mu \mathrm{M})$, reference protein (Se155-4 single chain variable fragment, $\left.\mathrm{P}_{\text {ref }}, 1 \mu \mathrm{M}\right)$ and PNAG hexamer $(\mathrm{L}, 60 \mu \mathrm{M})$. 


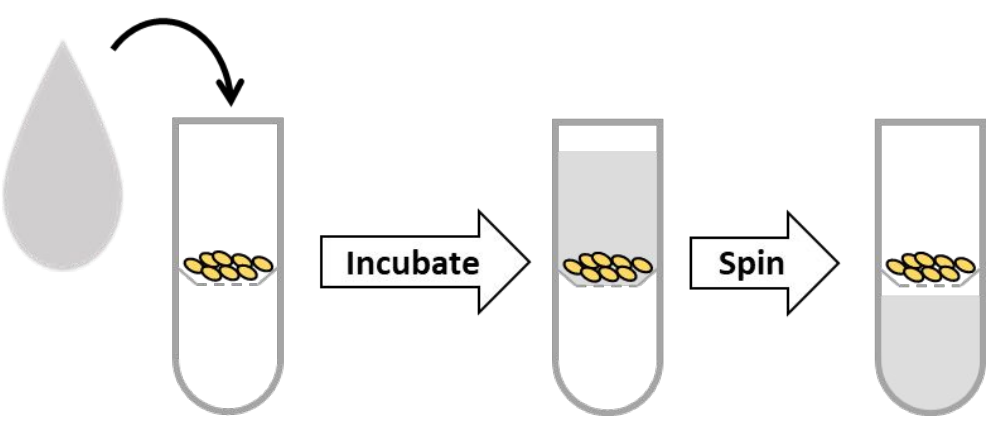

Figure S4. Spin filter tubes allow separation of solution from cells and cell-associated objects during bacterial PNAG binding assay. Each step in the binding assay involves resuspension of cells, followed by a standard incubation time and centrifugation. The filtrate can then be collected from the collection tube and fluorescence signal quantified. 

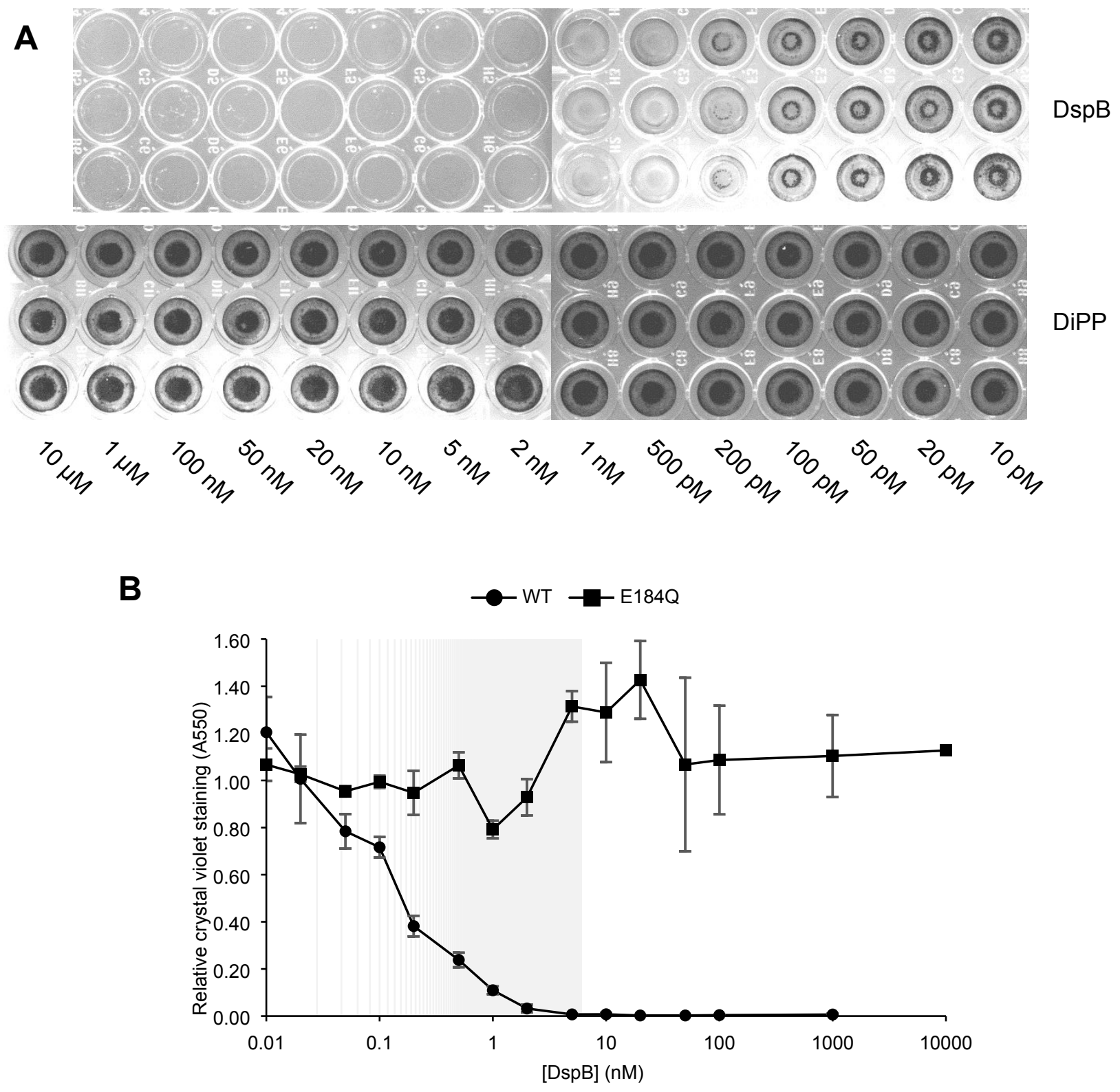

Figure S5. Biofilm dispersal activity of DiPP. Biofilms of E. coli csrA::kanB cells were grown in a 96-well plate and treated for 30 minutes with varying concentrations of DspB or DiPP before being washed with water and stained by crystal violet. (A) Wells containing crystal violet-stained biofilms after enzyme treatment. Note that DiPP was added in concentrations up to $10 \mu \mathrm{M}$ while DspB was not added in concentrations above $1 \mu \mathrm{M}$. (B) Absorbance at $550 \mathrm{~nm}$ of resolubilized crystal violet was used to plot DspB concentration-dependant dispersal of biofilm. Data was normalized to control wells containing biofilms not treated with enzyme. DiPP data points are more highly variable; this may be due to edge effects or differential biofilm growth in separate wells. 
A

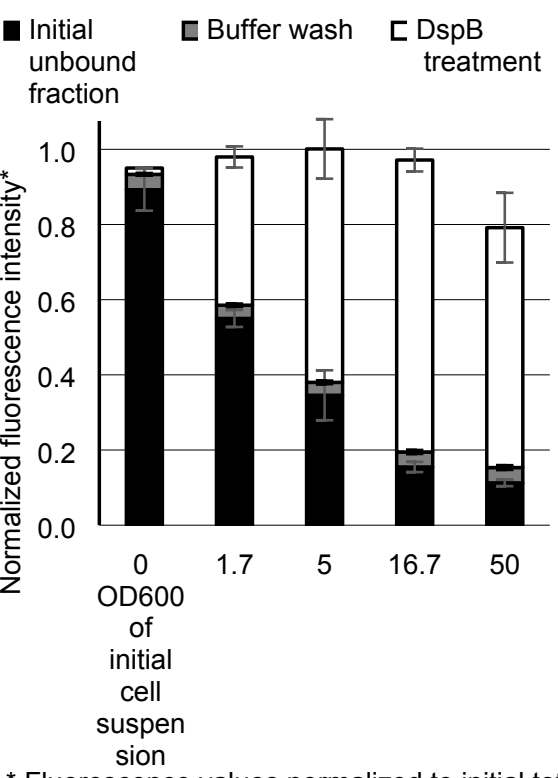

B
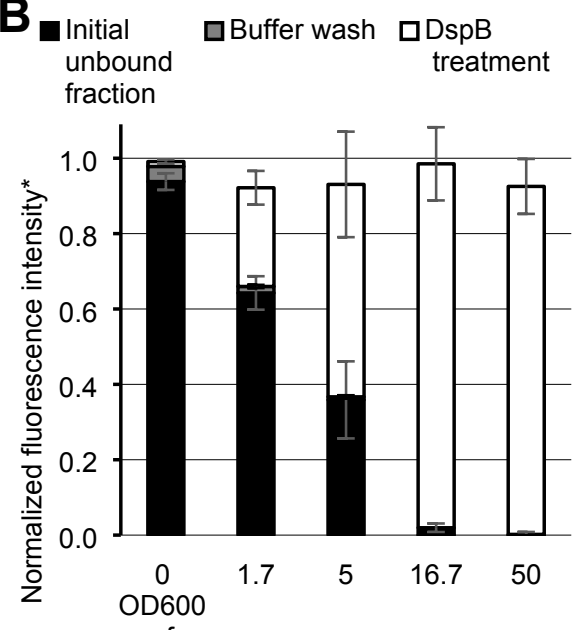

of initial

cell

suspen

sion

* Fluorescence values normalized to initial total signal of GFP-DiPP labelling solution

Figure S6. Fluorescence present in the three sequential filtrates obtained from each bacterial PNAG binding assay sample. Fluorescence values are normalized to the intensity of the initial solution used to label the cells; totalling the 3 collected filtrates post-labelling (unbound, buffer wash, DspB treatment) should reconstitute initial signal. Data from 3 separate experiments. (A) Cells labelled with monomeric GFP-DiPP. (B) Cells labelled with streptavidinbound tetrameric GFP-DiPP. Note the residual initial unbound fraction persisting at high cell numbers. Aggregated data of DspB treatment fractions are shown in Fig. 2E, and statistically significant differences between GFP-DiPP constructs at high cell concentrations by two-tailed T-test $(\mathrm{P}<0.05)$ were noted. All error bars represent standard deviation between replicates. 


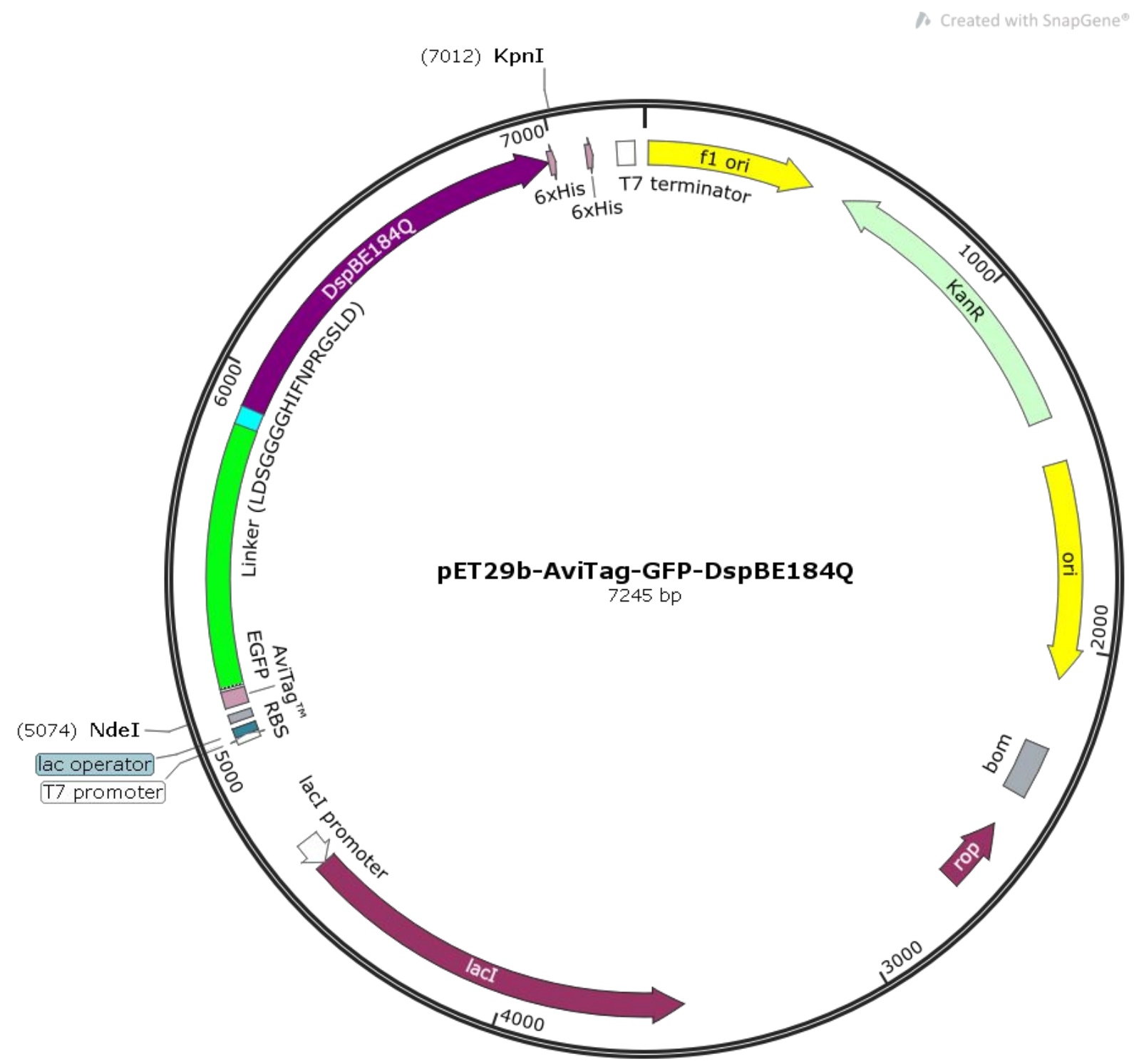

Figure S7. Plasmid map of AviTag-GFP-DspBE184Q. Vector backbone used was pET29b, originally from a plasmid containing DspBE184Q with a C-terminal 6xHis tag (designated as pCR3 ${ }^{1,2}$ ). Gene of interest flanked by NdeI and KpnI restriction sites. Figure made in SnapGene Viewer 4.0.5. 


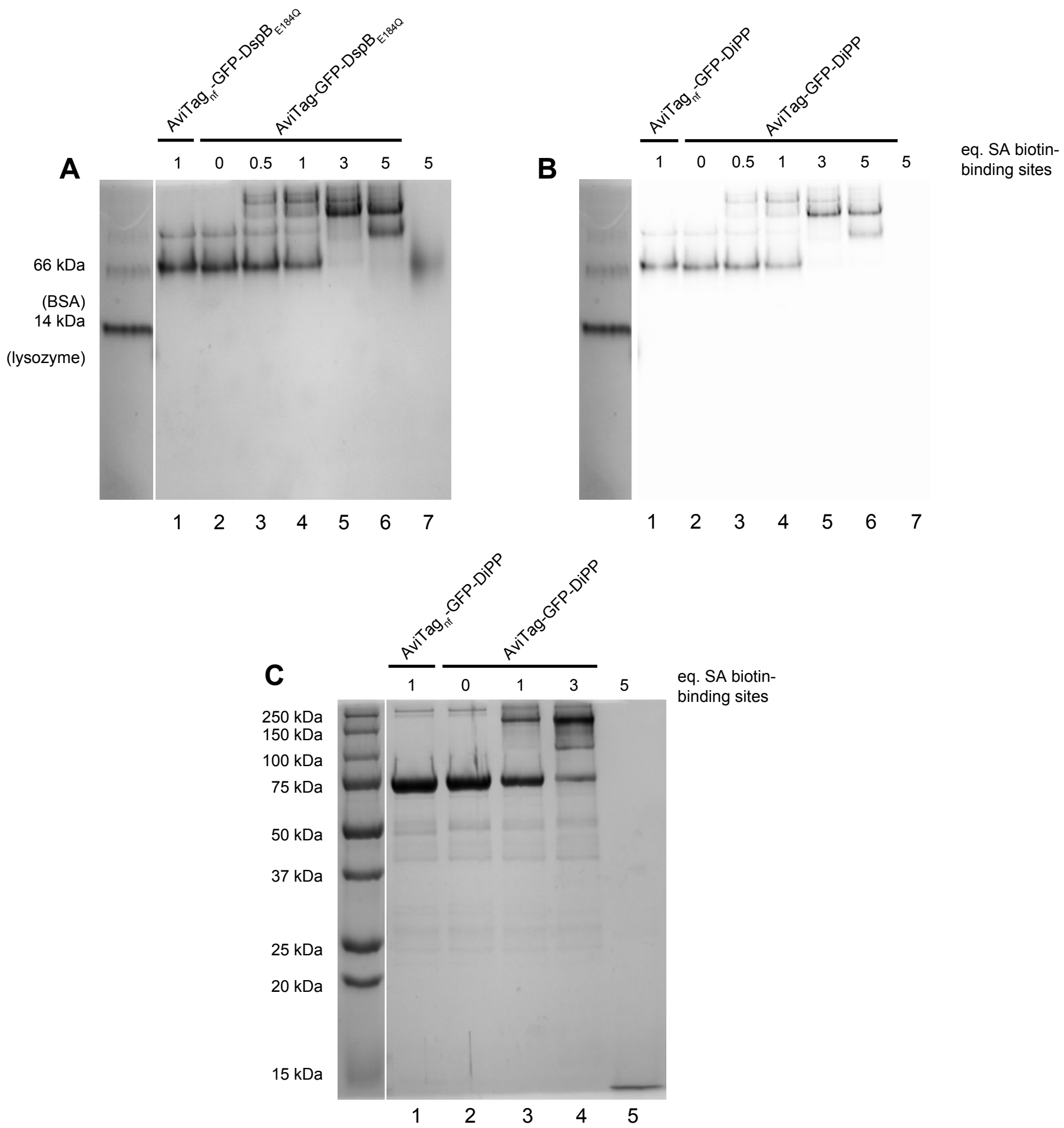

Figure S8. Gel shift assay measuring extent of biotinylation. GFP-DiPP with N-terminal AviTag (or non-functional AviTag $_{\text {nf }}$ with acceptor lysine replace with alanine) was incubated with the biotin ligase BirA. Post-reaction, streptavidin (SA) was incubated with the reaction mixture and the formation of higher MW species was viewed by gel electrophoresis. Varying stoichiometric equivalents of SA were added; reported as SA biotin-binding sites based on the tetrameric nature of streptavidin. (A) Native-PAGE of samples stained with Coomassie R. Note the formation of high MW species and the complete shift of the $70 \mathrm{kDa}$ band (lane 5) indicating complete biotinylation. With 
excess SA (lane 6), lower MW species are seen indicating incomplete saturation of SA. (B) Native-PAGE of samples viewing GFP fluorescence. (C) SDS-PAGE of samples stained with Coomassie R. SA added after denaturation of proteins to preserve high MW species.
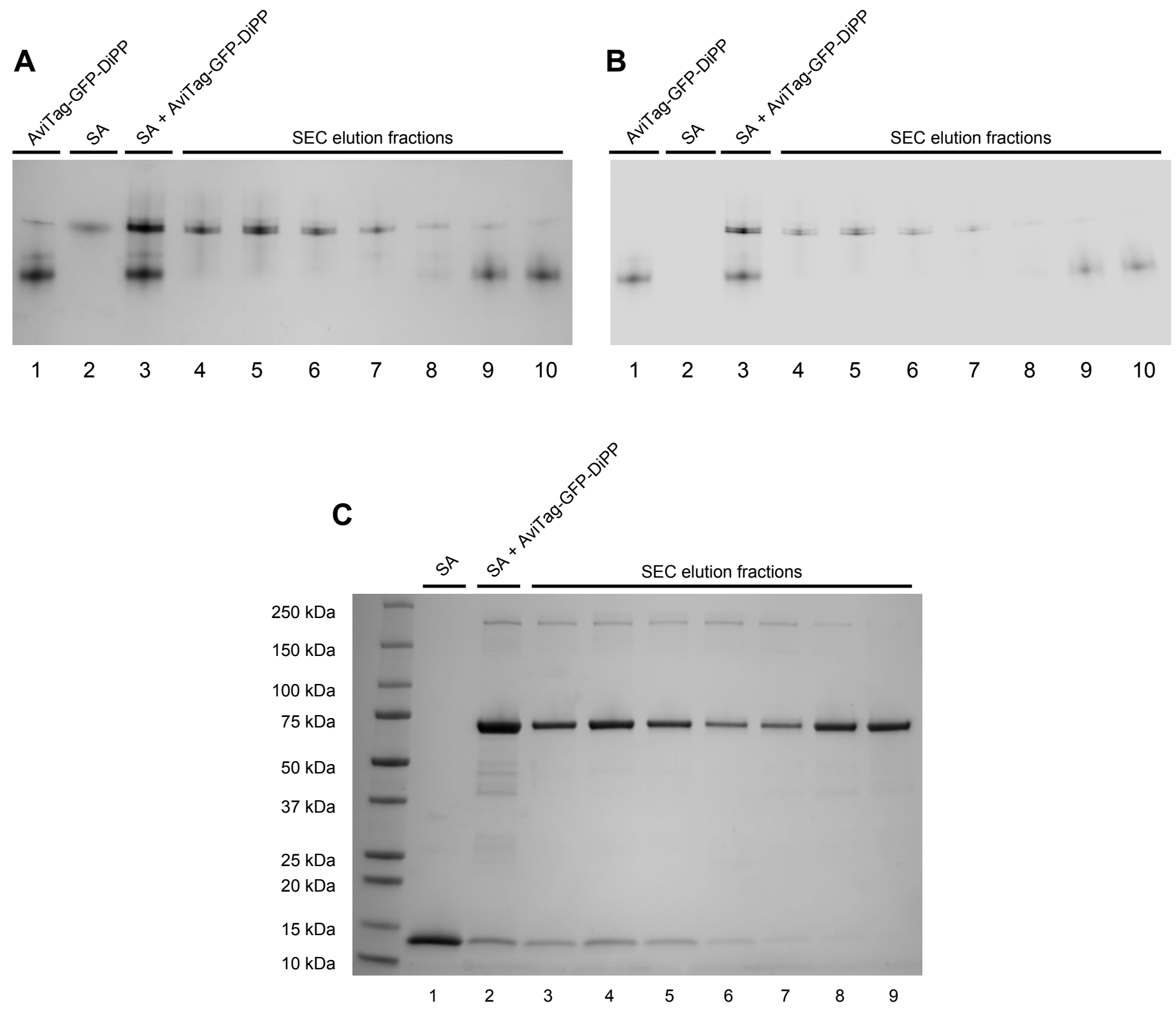

Figure S9. FPLC fractions of tetrameric probe. GFP-DiPP with biotinylated N-terminal AviTag was incubated with 1.5 equivalents of streptavidin (SA). The reaction was separated by size-exclusion chromatography on a Bio-Rad NGC. (A) Native-PAGE of fractions stained with Coomassie R. Note the presence of high MW species (lanes 4 through 7). Initial sample in lane 3. (B) Native-PAGE of samples viewing GFP fluorescence. Initial sample in lane 3. (C) SDS-PAGE of samples stained with Coomassie R. Note the presence of SA (13 kDa band) in earlier size exclusion fractions (lanes 3 through 7). Initial sample in lane 2. 


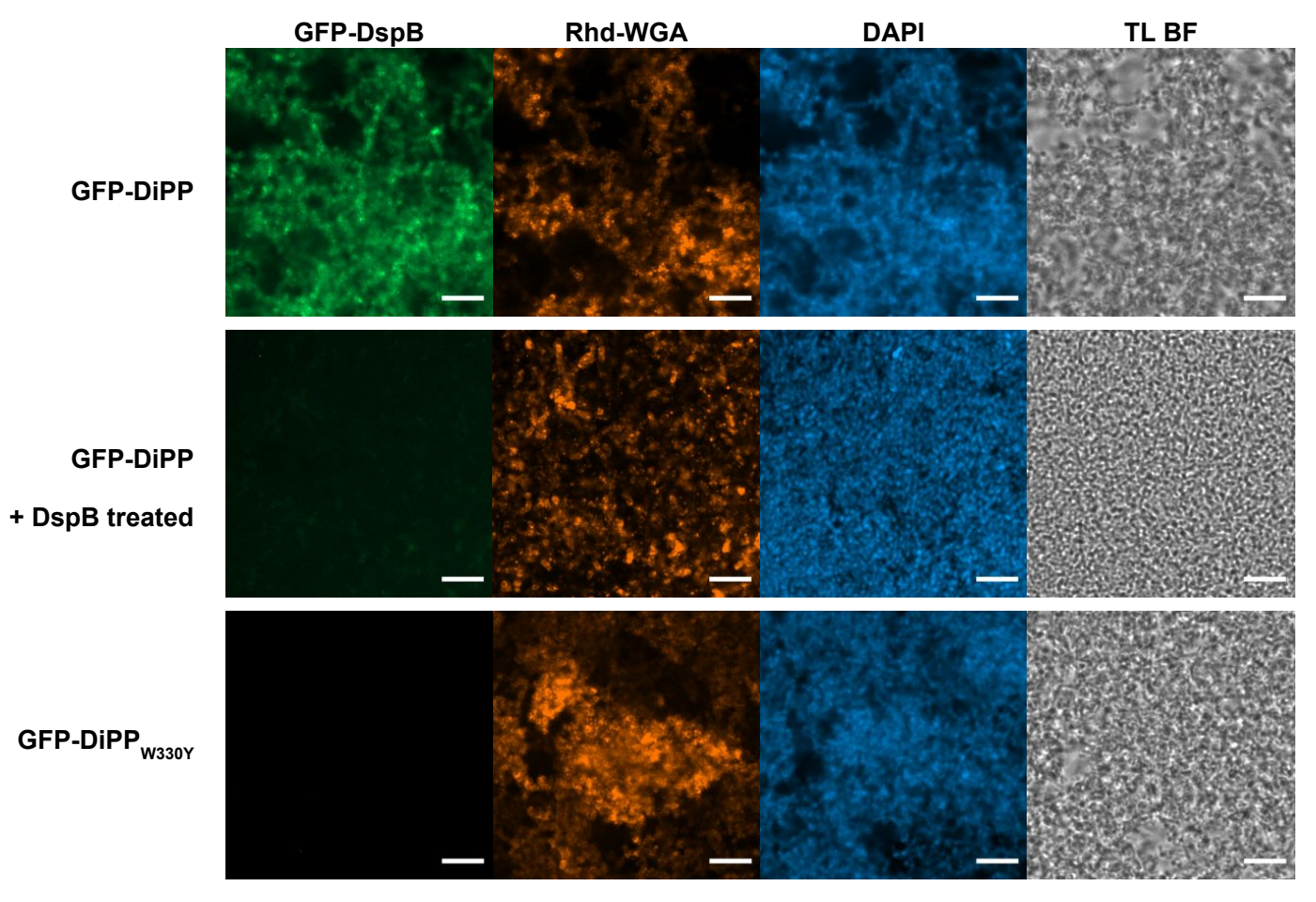

Figure S10. E. coli $\operatorname{csr} A:$ kanB biofilms labelled with GFP-DiPP and Rhd-WGA. Biofilms were grown on a coverslip in a standing culture and labelled with GFP-DiPP and Rhd-WGA before immobilization under agarose and imaging by spinning-disk confocal microscopy. Biofilms labelled with (A) GFP-DiPP, and after agarose immobilization were (B) treated with DspB. Other samples were labelled with (C) non-binding GFP-DiPP ${ }_{\mathrm{W} 300 \mathrm{Y}}$. Scale bars are $10 \mu \mathrm{m}$. 

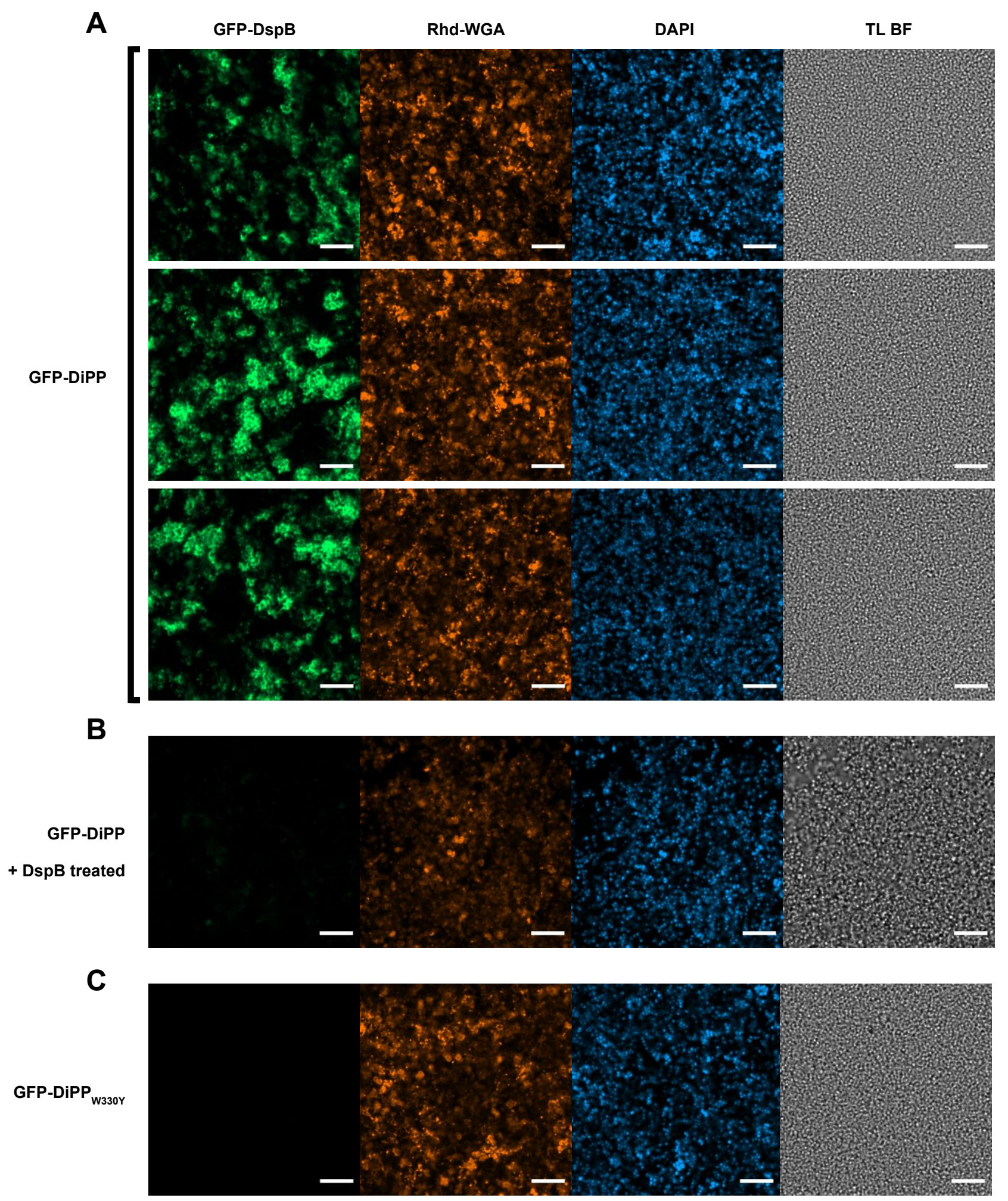

Figure S11. S. epidermidis SE801 biofilms labelled with GFP-DiPP and Rhd-WGA. Biofilms were grown on a coverslip in a standing culture and labelled with GFP-DiPP and Rhd-WGA before immobilization under agarose and 
imaging by spinning-disk confocal microscopy. Biofilms labelled with (A) GFP-DiPP, and after agarose immobilization were (B) treated with DspB. Other samples were labelled with (C) non-binding GFP-DiPP $\mathrm{W}_{\mathrm{W} 00 \mathrm{Y}}$. Scale bars are $10 \mu \mathrm{m}$.

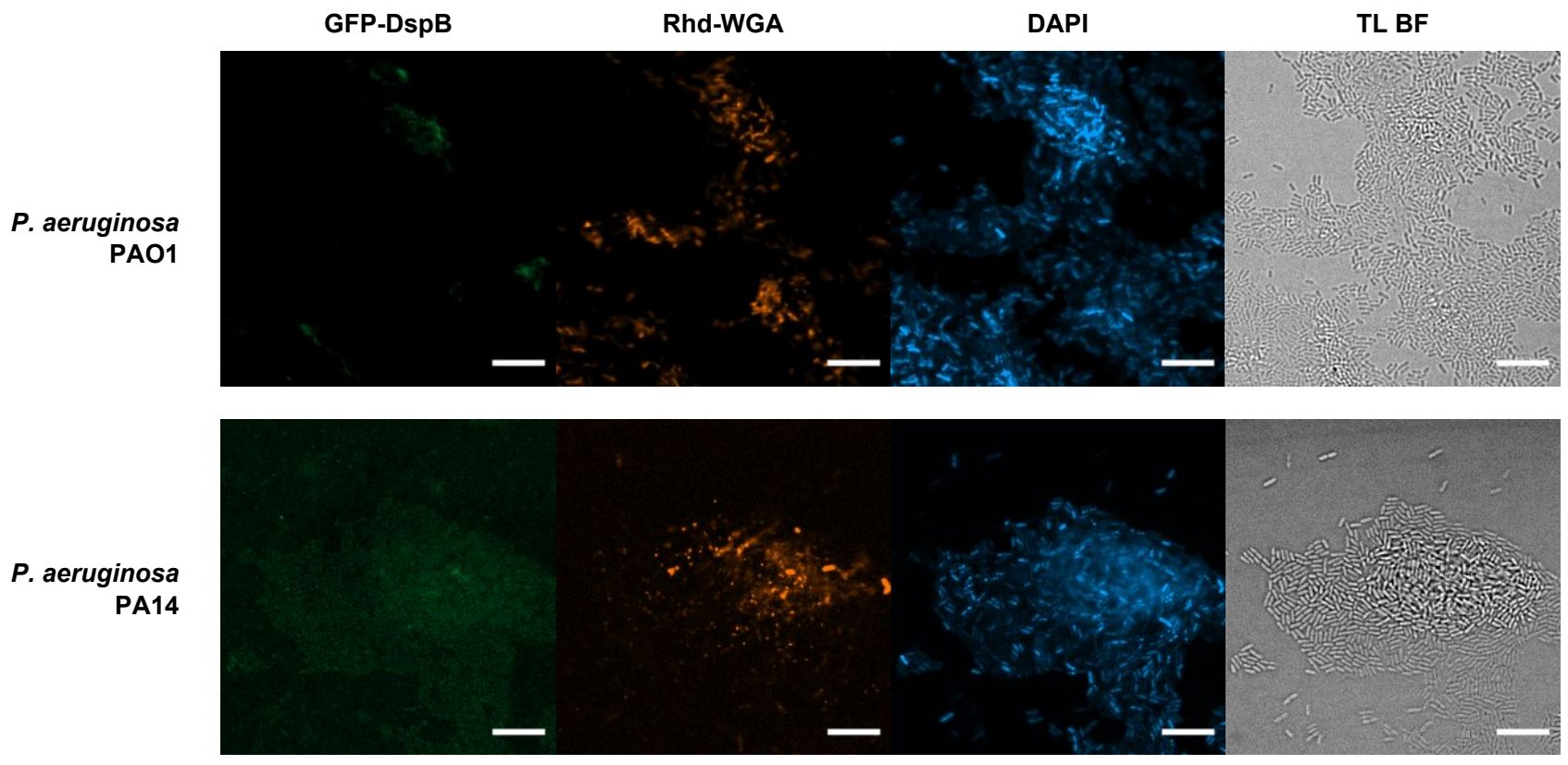

Figure S12. P. aeruginosa biofilms labelled with GFP-DiPP and Rhd-WGA. Biofilms were grown on a coverslip in a standing culture and labelled with GFP-DiPP and Rhd-WGA before immobilization under agarose and imaging by spinning-disk confocal microscopy. Two strains of $P$. aeruginos $a$ were grown (A) PAO1 with a biofilm composed predominantly of the Psl polysaccharide, and (B) PA14 with a biofilm composed predominantly of the Pel polysaccharide. Scale bars are $10 \mu \mathrm{m}$. 
A
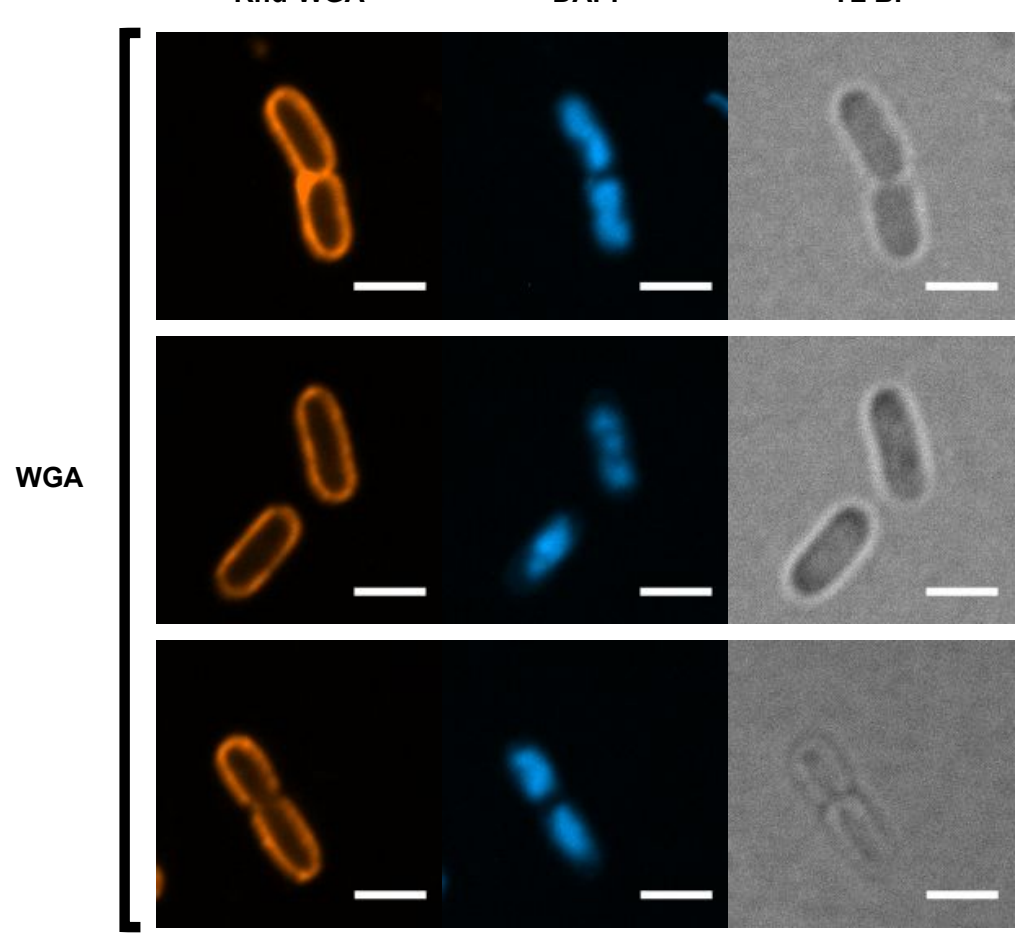

B

WGA

+ DspB treated

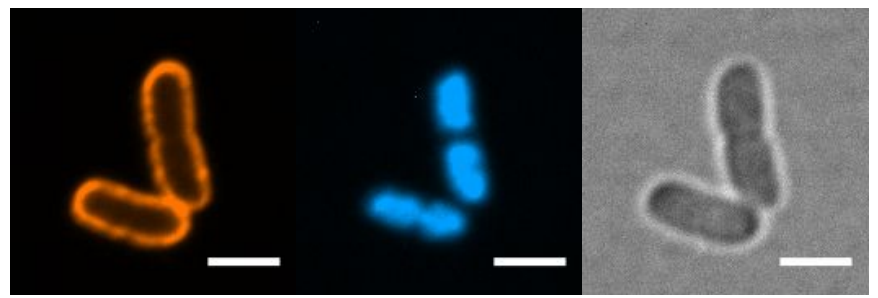

\section{C}

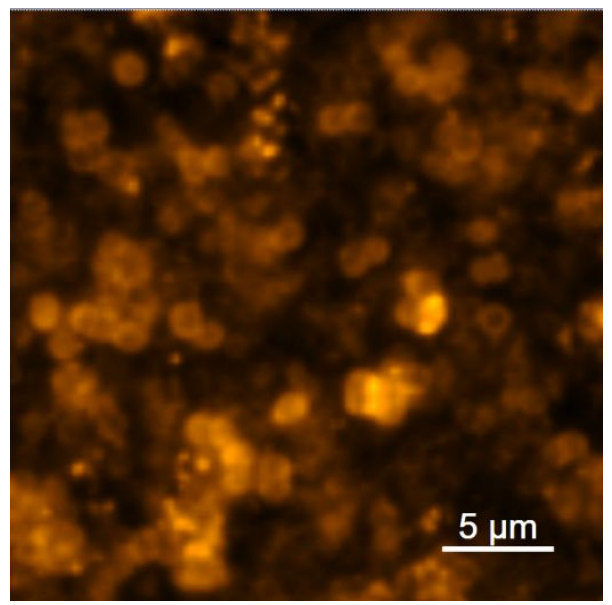

D

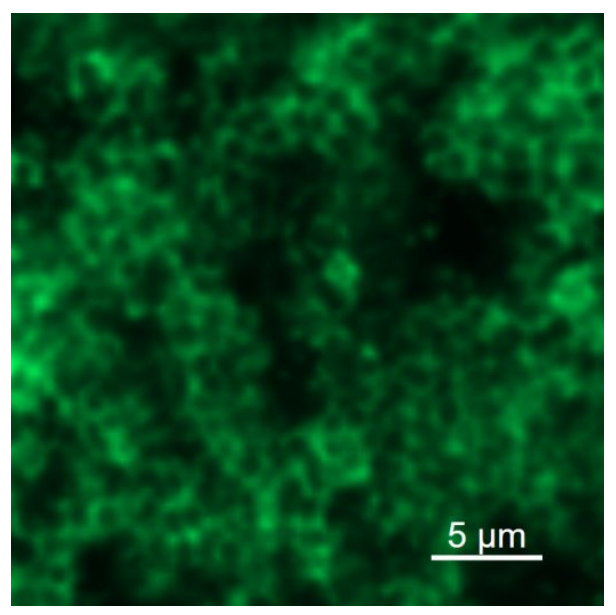

Figure S13. WGA labelling of cell surfaces. E. coli $\operatorname{csr} A:$ kanB cells in early log-phase labelled with GFP-DiPP. Cells were taken from a 2 hour culture and labelled with Rhd-WGA and DAPI before immobilization on agarose and imaging by spinning-disk confocal microscopy. Cells labelled with (A) Rhd-WGA, and after agarose immobilization were (B) treated with DspB. Note the persistence of WGA labelling. Scale bar is $2 \mu \mathrm{m}$. Zoomed-in views of S. epidermidis SE801 biofilms showing (C) Rhd-WGA and (D) GFP-DiPP labelling. Note the differences in staining patterns, with WGA displaying the characteristic "ring-like" staining, while GFP-DiPP appears to label more profusely in gaps between cells. Scale bars are $5 \mu \mathrm{m}$. 


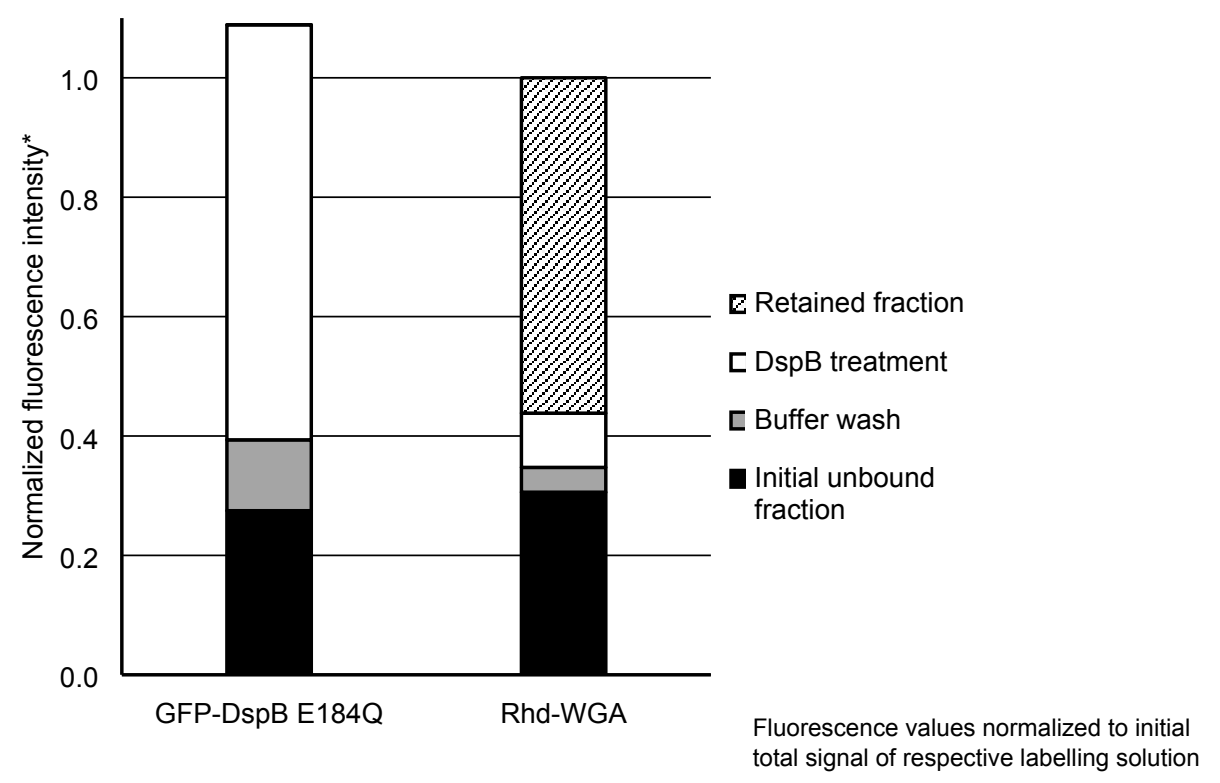

$00+$

Figure S14. Bacterial PNAG binding assay with Rhd-WGA. Fluorescence values are normalized to the intensity of the initial solution used to label the cells; totalling the 3 collected filtrates post-labelling (unbound, buffer wash, DspB WT treatment) should reconstitute initial signal if binding is PNAG-dependant. Note the fraction of RhdWGA unable to be released from cells upon DspB treatment. Data from 1 experiment. 


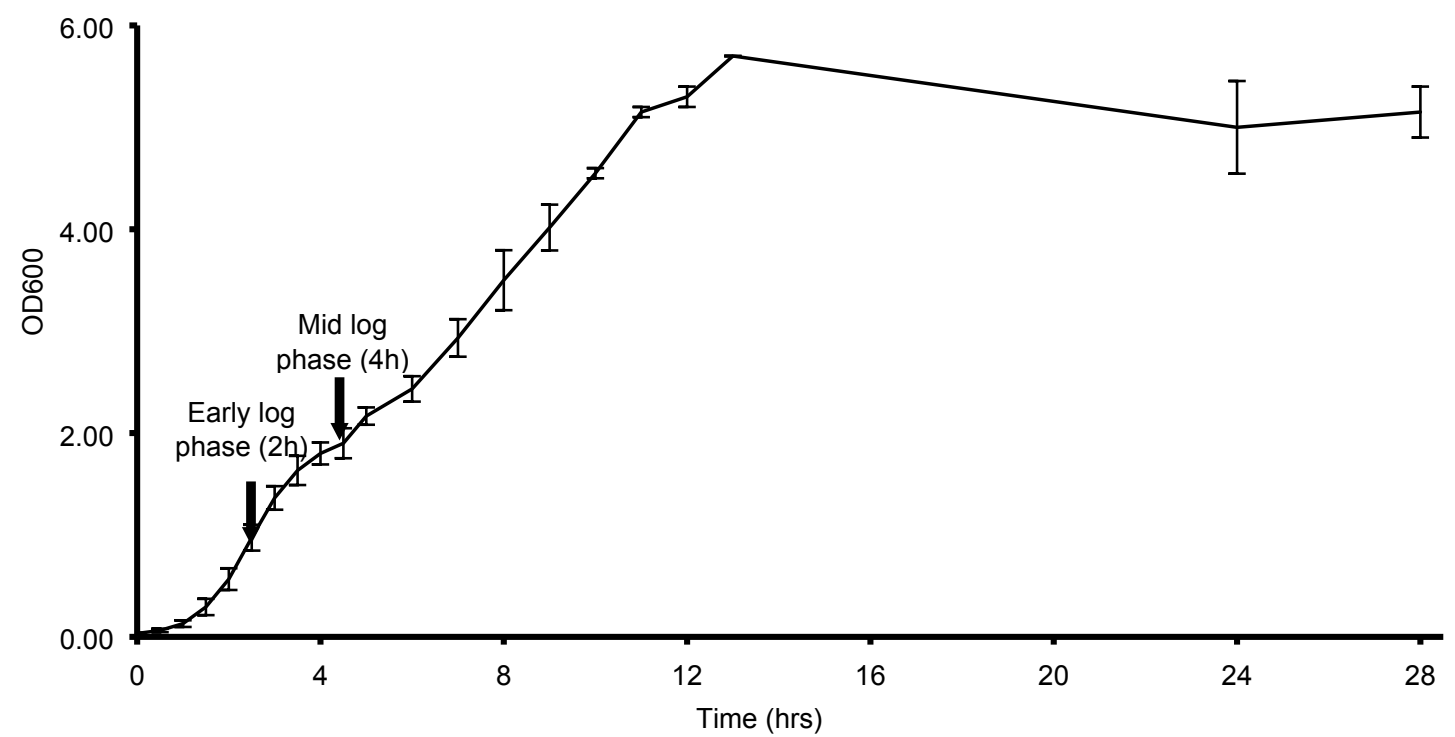

Figure S15. Growth curve of E. coli $\operatorname{csr} A: \because k a n B$. An overnight culture was inoculated into $50 \mathrm{~mL}$ of LB(Miller) media and grown at $37^{\circ} \mathrm{C}$ with shaking. Optical density $\left(\mathrm{OD}_{600}\right)$ measurements were taken of aliquots at specified timepoints. Significant cell aggregation was noticed around 3-4 hours, increasing up until 12 hours. Cells were vigorously resuspended before OD measurements to avoid scattering effects from cellular aggregates. 


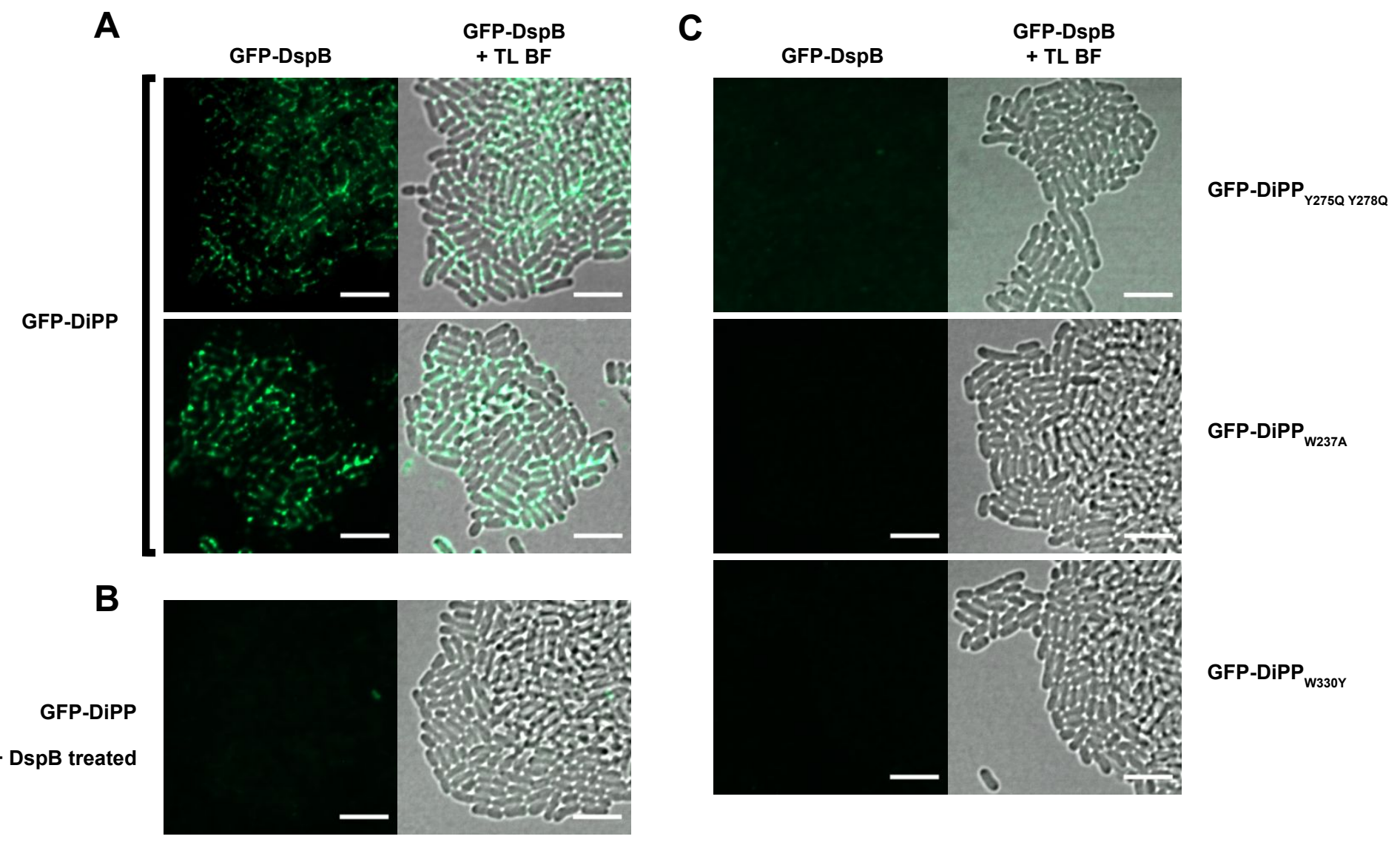

Figure S16. E. coli csrA::kanB cells in mid log-phase labelled with GFP-DiPP. Cells were taken from a 4 hour culture and labelled with GFP-DiPP before immobilization on agarose and imaging by spinning-disk confocal microscopy. Cells labelled with (A) GFP-DiPP, and after agarose immobilization were (B) treated with DspB. Other samples were labelled with $(\mathrm{C})$ non-binding GFP-DiPP $\mathrm{W}_{\mathrm{W} 300 \mathrm{Y}}$. Scale bars are $5 \mu \mathrm{m}$. 

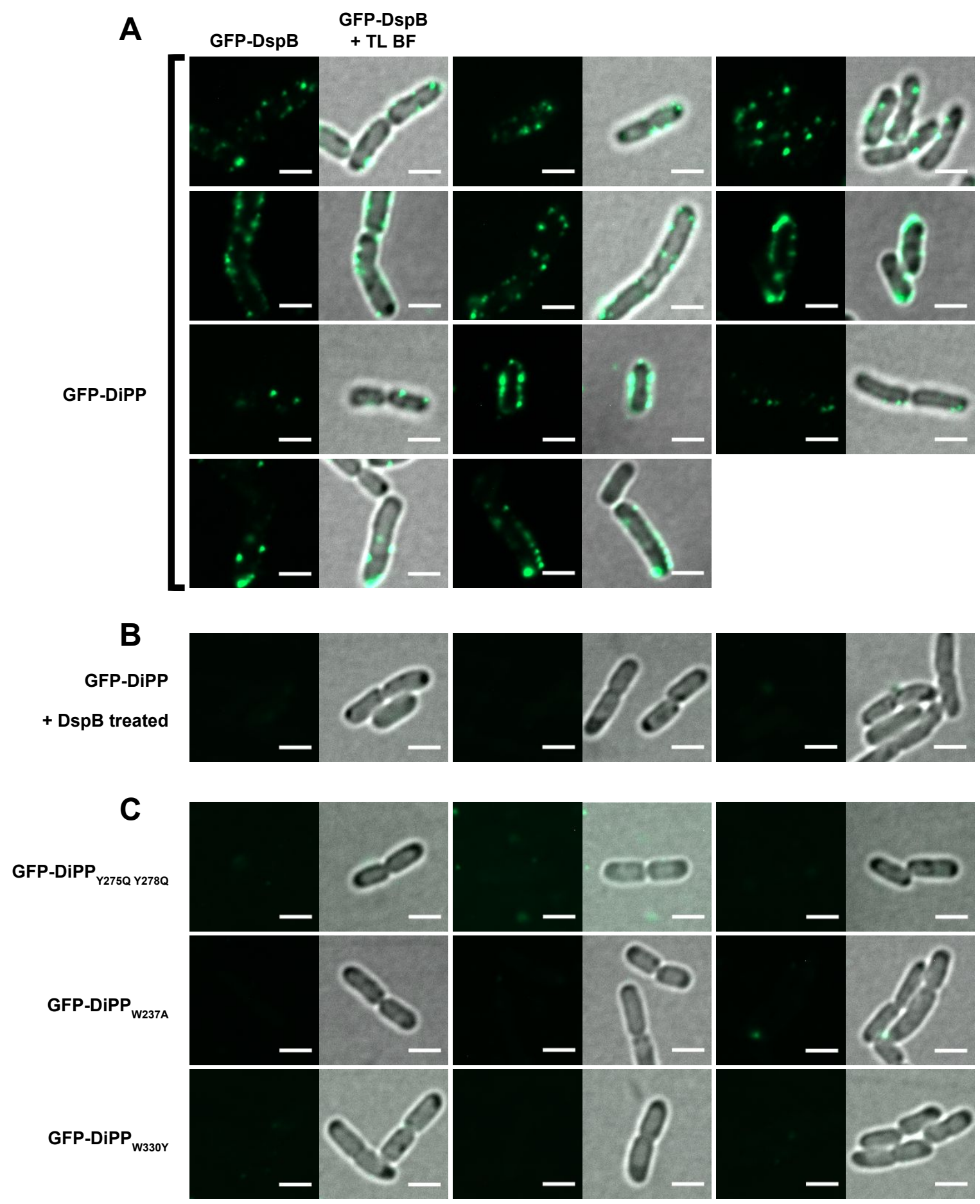

Figure S17. E. coli csrA::kanB cells in early log-phase labelled with GFP-DiPP. Cells were taken from a 2 hour culture and labelled with GFP-DiPP before immobilization on agarose and imaging by spinning-disk confocal microscopy. Cells labelled with (A) GFP-DiPP, and after agarose immobilization were (B) treated with DspB. Other samples were labelled with $(\mathrm{C})$ non-binding GFP-DiPP $\mathrm{W}_{300 \mathrm{Y}}$. Scale bars are $2 \mu \mathrm{m}$. 
Table S1.

\begin{tabular}{|l|l|l|}
\hline \multicolumn{3}{|c|}{ Calculated dissociation constants from in vitro binding assays } \\
\hline & PNAG oligomer & $\mathrm{K}_{\mathrm{d}}(\mathrm{mM})$ \\
\hline \multirow{3}{*}{ ESI-MS binding assay } & $4-\mathrm{mer}$ & $1.0 \pm 0.4$ \\
\cline { 2 - 3 } & $6-\mathrm{mer}$ & $1.0 \pm 0.3$ \\
\cline { 2 - 3 } & $8-\mathrm{mer}$ & $1.5 \pm 0.5$ \\
\hline \multirow{2}{*}{$\begin{array}{l}\text { Fluorescence quenching } \\
\text { binding assay }\end{array}$} & $4-\mathrm{mer}$ & $6 \pm 1$ \\
\cline { 2 - 3 } & $5-\mathrm{mer}$ & $10 \pm 1$ \\
\hline
\end{tabular}

